\title{
Oyun İncelemelerinde Ludoloji - Narratoloji Tartışması ve Alternatif Kuramsal Arayışlar
}

\section{Oğuz Özgür Karadeniz}

doktora öğrencisi

muğla sıtkı koçman üniversitesi oguzozgurkaradeniz@gmail.com

\begin{abstract}
The Ludology vs. Narratology Debate and Alternative Theoretical Approaches in Game Studies

The study of digital games by social sciences and humanities have been the subject of an academic debate since early 2000s. The questions of what games are, how they can/should be studied, and by implication of the answers given to these questions, who can/should study them resulted in the well-known debate in the field named "Ludology vs. Narratology". Both approaches which give their names to this debate were criticized for being overly formalistic and reductive. Through a literature review covering both parties and their critiques, this study aims to examine and discuss these two approaches, their critiques, and two alternative theoretical frameworks, Alexander R. Galloway's algorithmic culture, and lan Bogost's procedural rhetoric, which seem promising in their potential to overcome the formalist limitations of these approaches.
\end{abstract}

keywords: narratology, ludology, algorithmic culture, procedural rhetoric, game studies

Bu makaleye referans vermek için: Karadeniz O. Ö., (2017). Oyun İncelemelerinde Ludoloji - Narratoloji Tartışması ve Alternatif Kuramsal Arayışlar. Galatasaray Üniversitesi İleti-ş-im Dergisi, 27, 57-78. 


\section{Résumé}

\section{Le débat de ludologie vs. narratologie et approches théoriques alternatives aux études de jeu}

Étant donné que les jeux numériques sont des produits éminents de la culture visuelle postmoderne, leur étude menée par les sciences sociales et les sciences humaines a fait l'objet d'un débat académique depuis le début des années 2000. Les questions de ce que les jeux sont et comment ils peuvent / doivent être étudiés et par implication des réponses qui leur sont données, qui peut / doit les étudier, a abouti au débat bien connu dans le domaine intitulé "Ludologie contre Narratologie". Les deux approches qui donnent leur nom au débat ont été critiquées pour être excessivement formalistes et réductrices. À travers une revue de la littérature couvrant les deux parties et leurs critiques sur le débat "Ludologie contre Narratologie», cette étude vise à examiner et discuter ces deux approches et leurs critiques, ainsi que deux cadres théoriques; la culture algorithmique d'Alexander R. Galloway et la rhétorique procédurale d'lan Bogost, qui promettent de surmonter les limites formelles de ces deux approches.

mots-clés : narratologie, ludologie, culture algorithmique, rhétorique procédurale, études de jeu

\section{Öz}

Postmodern görsel kültürün önde gelen ürünlerinden olan dijital oyunların sosyal ve beşeri bilimler tarafından incelenmesi akademide 2000'lerin başından bu yana süregelen bir tartışmanın konusu olmuştur. Oyunların "ne olarak", "nasıl", ve bu sorulara verilen yanıtlar dolayımıyla, "kim tarafından" incelenebileceği ve incelenmesi gerektiği "Ludoloji - Narratoloji Tartışması" olarak adlandırılan ünlü tartışmaya yol açmıştır. Tartışmaya adını veren iki yaklaşım da indirgemecilik ve aşırı biçimcilikle eleştirilmiştir. Bu çalışma, Iudoloji - narratoloji tartışmasının taraflarını ve eleştirilerini kapsayan bir alanyazın taraması yaparak bu iki kavramsal çerçeveyi, bunlara yapılan eleştirileri ve bu yaklaşımların biçimciliklerinden kaynaklı sınırıııklarını aşma potansiyeli barındıran iki farklı kuram olan Alexander R. Galloway'in algoritmik kültür ve lan Bogost'un prosedürel retorik kavramlaştırmalarını tanıtmak ve tartışmak amacını taşımaktadır.

anahtar kelimeler: narratoloji, ludoloji, algoritmik kültür, prosedürel retorik, oyun çalışmaları 


\section{Giriş}

Game Studies dergisinin baş editörü Espen Aarseth (2001), derginin ilk sayısı için yazdığı giriş yazısında oyun çalışmaları ile ilgili akran denetimli ilk derginin yayın hayatına girdiği ve oyunlara ilişkin ilk uluslararası akademik konferansın yapıldığı 2001 yılını "bilgisayar oyunu çalışmalarının birinci yıı" olarak niteler. IIlk bilgisayar oyunu Spacewar! (Russel, 1962) kırk yaşına girmiş ve ticari oyunlar yapılmaya başlayalı otuz yı geçmiş olmasına rağmen akademinin dijital oyunları kültürel bir alan olarak ciddiye almaya başlaması 2001 yılında olmuştur (Aarseth, 2001).

Oyun çalışmalarının bir (inter)disiplin veya Espen Aarseth'in 2006 yılındaki nitelendirmesiyle bir akademik alan olarak kabul görmesi, Aarseth'in kendisinin de içinde yer aldığı bir mücadelenin sonucudur ve bu mücadelenin amacı oyunların akademi tarafından ciddiye alınmasını sağlamaktan ibaret değildir. Oyun çalışmaları alanındaki bu mücadelede söz konusu olan, dijital oyunların kimler (hangi kişi, disiplin ve kurumlar) tarafından ve nasıl (kimlerin denetiminde ve öncelikli olarak hangi disiplinlerin kuramsal/kavramsal araçlarıyla) çalışılması gerektiğidir. Oyun çalışmalarında ludoloji ve narratoloji olarak bilinen iki rakip ekolün halen sürmekte olan çatışması bu alan mücadelesi içinde ortaya çıkmıştır.

1990'lardan bu yana gelişmekte olan ve "Ludoloji - Narratoloji Tartışması" olarak bilinen tartışmanın kuramsal ayağı, oyunların ne olduğuna ilişkin ontolojik bir varsayım üzerinden onların hangi kuramlarla çalışılabileceğini sorgular. Narratolojinin başlıca temsilcileri olan Henry Jenkins (2004), Brenda Laurel (1991) ve Janet H. Murray (1997) oyunların drama, film, roman gibi anlatı temelli medya ile aynı ekolojiye ait olduğunu iddia ederler. Bu yaklaşım, ilişkili olduğu mecralar nedeniyle oyunların incelenmesinde mevcut anlatı medyasına dair analitik araçların gerektiğinde ampirik kanıtlara göre ayarlanarak kullanılabileceğini savunur (Raessens, 2006, s. 55). Buna karşın ludolojinin aralarında Espen Aarseth (1997), Jesper Juul (2001), Markku Eskelinen (2001), ve Gonzalo Frasca'nın (2003) da bulunduğu başlıca temsilcilerinin genel görüşü anlatı ile oyunlar arasında farklıık olmadığını iddia etmenin iki ortamı da indirgemek olduğudur. Oyunlar ve anlatılar aralarındaki benzer ve ortak yönlere rağmen temelde farklıdır ve bu nedenle mevcut disiplinlerin kuramsal araçları oyunların analizi için yetersizdir.

Bu çalışma ludoloji-narratoloji tartışmasını eleştirel bir gözle incelemek amacını taşımaktadır. Bu amaçla narratoloji ve ludoloji yaklaşımlarının temel metinleri ve tartışmayı aktaran kaynakların yanında tartışmanın taraflarına ve geneline yapılan eleştirileri de kapsayan bir alanyazın taraması yapılmıştır. Öncelikle tartışmanın tarafı olan narratoloji ve ludoloji yaklaşımları incelenecektir. Bu yaklaşımların kuramsal ve yöntemsel çıkmazları ve tartışmanın alana etkileri tartışıldıktan sonra bu çıkmazlara çözüm olabilecek açılımlar barındıran iki kavramsallaştırma olarak seçilen Alexander R. Galloway'in (2006) algoritmik kültür ve lan Bogost'un (2006; 2007) prosedürel retorik kavramları ele alınacaktır. 


\section{Narratoloji: Metin Olarak Oyunlar}

Coward ve Ellis'e (1977, s. 1) göre 20. yüzyllın entelektüel alandaki en önemli özelliklerinden biri dilin incelenmesinin toplumsallığı anlamada yeni ve önemli bir yol olarak benimsenmesidir. Yapısalcı kuramların 1960'ların ortalarında özellikle Fransa'da etkisini arttırmasıyla sosyal bilimler ve hümanistik disiplinlerde "anlatısal dönüş" adı verilen akım yaşanmıştır (Herman, 2009, s. 23). Dilbilim "psikoloji, eğitim, sosyal bilimler, siyasi düşünce ve politika analizi, sağlık araştırmaları, hukuk, teoloji ve bilişsel bilim" gibi çoğu disiplinin sınıllarını aşarak yaygın ancak tartışmalı bir kavramsal araç haline gelmiştir (Hyvärinen, 2006, s. 20).

Narratolojinin temellerini Rus biçimcilerinin attığı söylenebilir (Herman, 2009, s. 26-27). Örneğin; Boris Tomashevskii'nin bağlı ve özgür olaylar kavramlaştırması, Roland Barthes'ın çekirdek ve katalizör, Seymour Chatman'ın ise çekirdek ve uydu olarak adlandırdığı merkez ve çevre olay kavramlaştırmalarının temelini oluşturur. Benzer biçimde Tomashevskii'nin motifler üzerine çalışması, Viktor Shklovski'nin yapısal narratolojinin temelindeki varsayımlardan biri olan fabula/suje yani anlatılanın ne olduğu ve nasıl anlatılığı arasındaki ayrımını etkilemiştir (Herman, 2009, s. 26-27). Modern anlatı kuramının bir diğer biçimci öncüsü Vladimir Propp'tur. Propp'un halk öyküleri üzerine yaptığı Morphology of a Folktale isimli çalışmasında dramatik karakterler ile onların öyküdeki değişmeyen fonksiyonları arasında yaptığı ayrım yapısal teorilerde karakterlerin aktant yani çeşitli karakterlerin yerine getirdiği roller olarak ele alınmasının temelini oluşturmuştur. Örneğin Algirdas Julien Greimas, bütün anlatısal aktörleri altı aktant'a indirgediği tipolojisini bu kavramlaştırmaya dayanarak yapar (Herman, 2009, s. 27-28).

Anlatı kuramı ve dilbilimsel dönemeç üzerindeki diğer büyük etki İsviçreli dilbilimci Ferdinand de Saussure'den gelmiştir. Saussure'ün yapısal dilbilimi Batı düşüncesinde dilin nasıl görüldügünü tümden etkilemesi nedeniyle sosyal bilimlerde bir Kopernik devrimi olarak nitelendirilir (Harris ve Taylor, 2005, s. 210). Her ne kadar Saussure öncesinde de dilin insan rasyonalitesinde önemli bir araç olduğu kabul edilmekteydiyse de Saussure bu mantığın ötesine geçerek göstergeleri toplumsal gerçekliğin merkezine koymuştur (Harris ve Taylor, 2005, s. 210).

Saussure dilbilimi daha geniş bir göstergebilimin dille ilgilenen dalı olarak düşünmüştür. Dolayısıyla dilbilim langue'ı (dil) oluşturan göstergelerle ilgilenir. Saussure'ün (1974) ünlü formülasyonunda gösterge ses imgesini temsil eden bir gösteren ve ona karşılık gelen kavramı temsil eden bir gösterilenin oluşturduğu bir bütündür. Bu kavramlaştırmanın diğer bir önemli özelliği gösterilen ve gösteren arasındaki bağın tümüyle rastlantısal olmasıdır, gösterilen tamamen farklı bir gösteren tarafından da rahatlıkla gösterilebilir (Saussure, 1974, s. 67-68). Saussure'e göre her langue göstergelerden oluşan bir yapı, yani bir 
sistemdir. Parole (söz) adını verdiği konuşma ise langue'ı́n bir yansıması, "dışsal tezahürü" dür. Saussure'ün kendinden önceki dil çalışmalarına müdahalesi, langue ve parole arasında yaptığı bu ayrım ve odağı parole'dan langue'a taşımasıdır (Harris ve Taylor, 1997, s. 210-211).

Saussure'ün göstergeler ve dili biryapı olarak kavramlaştırması narratolojinin yapısalcı incelemenin bir alanı olarak kurulmasında büyük rol oynamış ve yapısalcı narratolojiyi amaçları, ele aldığı nesneleri ve yöntemi açısından şekillendirmiştir. Barthes ve Greimas gibi isimler Saussure'ün langue ve parole ayrımından etkilenerek anlatıları ortak bir gösterge sistemi kullanan mesajlar olarak alırlar (Herman, 2009, s. 27-28). Saussure'ün dilbiliminin dilin yapısal öğelerine ve dilin bağlı olarak kurulduğu prensiplere odaklanarak langue'ı parole'den daha ön plana koymasına benzer biçimde narratologlar da tekil anlatıların yorumlanmasından ziyade genel olarak anlatının incelenmesini ön plana almışlardır. Herman'ın (2009) da belirttiği gibi Barthes ve Greimas gibi araştırmacılar Saussure'dan etkilenerek tek tek anlatıları incelemekten çok anlatıları ve diğer kültürel ifade biçimlerini aşan ve onları örgütleyen kodlara önem vermişlerdir (s. 27-28).

Narratolojinin biçimcilerden etkilenmesinin bir sonucu olarak yapısalcı narratologlar anlatıların birçok biçim, mecra ve türde sunulabileceği düşüncesini benimsemiş, dolayısıyla anlatının analizi için bütünleştirici bir yaklaşımı savunarak anlatıların "anlık konuşmalar ve historiografik yazından görsel sanata, dansa ve mitik ve edebi geleneklere" uzanan çok sayıda bilişsel ve iletişimsel hareketi kapsayabileceğini kabul etmişlerdir (Herman, 2009, s. 24). Anlatı merkezli disiplinler arası araştırma ve öğretme etkinlikleri geçtiğimiz on yılda oldukça ilerlemiş; folklor, dil ve edebiyat ile ilgilenen araştırmacıları, film, dijital medya ve çizgi romanda öykü anlatımı üzerine çalışan kuramcıları ve diğer alanlardan anlatı ile ilgilenen araştırmacıları bir araya getiren kitap ve dergiler yayınlanmış, araştırma merkezleri kurulmuş, konferanslar gerçekleşmiştir (Herman, 2009, s. 23-24). Narratolojinin dijital oyunları da araştırma alanına almasının bir nedeninin devam etmekte olan bu disiplin aşıı gelişme olduğunu söylemek mümkündür.

Narratolojinin oyun incelemeleri için kullanımına ilk örneklerden biri olarak Brenda Laurel'in (1991) Computers as Theatre'ı verilebilir. Laurel bilgisayarları görülen, kontrol edilen ve oynanan şeyleri temsil etmeye uygun bir araç olarak görür. Ona göre bilgisayarın "ilginç potansiyeli hesaplama yapmasında değil insanların katılabileceği eylemleri temsil etme kapasitesindedir" (s. 1). Laurel buradan yola çıkarak bilgisayarları tiyatro ile ortak özellikleri olan bir ortam olarak ele alır. Bu benzetmede Laurel'e göre kullanıcı hem oyuncu hem de seyirci konumundadır (s. 16-17).

Janet H. Murray (1997) Hamlet on Holodeck'te bilgisayar teknolojisiyle bağlantılı olarak ortaya çıkan öykü anlatımındaki büyük dönüşümü anlatır. Yeni iletişim teknolojileri "anlatıya dayalı eğlence" için aralarında "shoot-'em-up video oyunu ve Internet rol yapma oyunlarının olduğu, sanal zindanlarından postmodern 
edebi hipermetne" uzanan yeni biçimler getirmiştir. Murray'e (1997) göre bu yeni biçimleri alışkın olduğumuz mecralarla karşılaştırmak yanlış olsa da bunların ilk nüveleri önceki mecralarda bulunabilir (s. 28-29):

[Y]eni anlatı gelenekleri yoktan var olmazlar. Belirli bir iletişim teknolojisi -yazılı basın, film kamerası, radyo - sahneye ilk çıktığında bizi yerimizden zıplatabilir ancak öykü anlatımı gelenekleri süreklidir ve hem biçim hem içerik olarak biri diğerine akar [...]

Şimdi anlatısal bilgisayarın ilk günlerinde, 20. yüzyıl romanlarının, filmlerin, ve oyunların nasıl doğrusal öykü anlatımının sınırlarını zorladığını görmekteyiz.

Dolayısıyla, Murray'e göre (1997) anlatılar daha dijital ortama taşınmadan çok biçimli yani birden çok yol izleyebilecek şekilde yazılmaya başlanmıştır. Böylelikle dijital anlatıların ortaya çıkması biri diğerinin öncülü olan bir dizi anlatı teknoloji ve biçiminden oluşan bir yolak üzerine yerleştirilebilir (s. 28-29). Oyunlar Murray'ın holodeck örneği ile temsil ettiği çok biçimli kurgu teknolojilerinden biri olarak bu zincirde bir halkadır.

Bu örneklerde görüldüğü gibi narratoloji, oyunları merkezinde öykü anlatımının olduğu diğer mecralara atıfla incelemekte ve bu ekolojinin bir parçası olarak görmektedir. Bu yaklaşım her ne kadar dijital medyanın kendine has yönlerini inkâr etmemişse de, oyunların etkileşimli anlatılar olarak düşünülmesi bu tartışmada ludoloji tarafında konumlanan araştırmacıların itirazlarına neden olmuştur.

\section{Ludoloji'nin Eleştirisi: Yeni Bir İnterdisipline Doğru}

"1800'lerin sonunda, demiryolları 'çelik atlar'dı. 1900'lerin başında, otomobiller 'atsız arabalar'dı. Ve 1900'lerin sonlarında, bilgisayar oyunları 'etkileşimli kurgular'dı."

David Myers, Play Redux: The Form of Computer Games (2001)

Ludoloji savunucuları oyunların anlatılar olarak incelenemeyeceğini iddia ederler. Ludolojistlere göre oyunlar anlatı veya dijital medyanın bir alt türü olarak değil, oyun olarak çalışılmalıdır. Ludolojinin temsilcileri bu amaçla fenomenoloji ve biçimcilikten yola çıkarak oyuna özgü biçimleri formüle eden bir kuramsal yaklaşım geliştirmeye çalışmışlardır.

Lankoski ve Björk (2015) biçim analizini (formal analysis) bir yapııın belirli öğelerinin ve bu öğeler arasındaki ilişkinin detaylı olarak incelenmesi olarak tanımlar. Bu incelemede incelenen yapıtın bağlamı ve diğer başka yapıtlarla ilişkisi göz önünde tutulabileceği gibi bağlamdan bağımsız olarak da ele alabilir. Ancak her durumda oyun herhangi bir oyuncudan veya tekil oynanışından bağımsız olarak ele alınmalıdır. Belirli oyuncu gruplarının oyunları ele alınsa bile hedeflenen bu oyuncuların oyunu nasıl oynadığı değil, bir sistem olarak oyunun oynanışıdır (Lankoski ve Björk, 2015, s. 23). 
Biçimsel analiz alanlar arasında farklılıklar göstermekte, her alanda o alanın biçimsel özelliklerini temel almaktadır. Alanın biçimsel özelliklerinin en önemlileri o alanın başat biçimini (significant form) oluşturur (Lankoski ve Björk, 2015, s. 24):

\begin{abstract}
Her [eserde] çizgi ve renkler belirli bir şekilde, belirli biçimlerde ve biçim ilişkilerinde bir araya gelerek estetik duygularımızı harekete geçirir. Çizgi ve renklerin bu ilişki ve kombinasyonlarına, estetik olarak heyecanlandıran bu biçimlere "Başat Biçim (Significant Form)" adını vermekteyim ve "Başat Biçim" bütün görsel sanat eserlerinde ortak bir niteliktir.
\end{abstract}

David Myers (2009) The Video Game Aesthetic: Play as Form'da oyunlardaki başat biçimi oynanış (gameplay) üzerinden kavramlaştııır. Bunun için öncelikle oyun oynamayı üç ayrı kategoriye ayırır: Bedenle oynamayı içeren lokomotor oyun (koşmak, zıplamak gibi); nesne oyunu, ki bu dijital oyunlardaki gibi kavramsal nesneleri de içerir; ve sosyal oyun, yani ötekilerle oynamak. Dahası oynanan nesneler ve oyun biçimleri de aynı şekilde üçe ayrılabilir: "Bedenlerimiz ve çevremiz arasındaki arayüzün manipülasyonu (lokomotor oyun)", "fiziksel hislerin kavramsal nesnelere dönüşümü (semiosis)", ve "ötekilerle ilişkilerin inşa, bakım ve devamını (sosyal oyun sırasında) içeren nesne ve biçimler" (s. 46).

Myers'a (2009) göre insan oyununun bir özelliği birlikte oynanan nesneden bağımsız olarak var olmayana veya var olandan farklı olana bir atıfta bulunmasıdır. Myers bunu değilveya karşıt-biçim (anti-form) olarak adlandıır. Bu bir sopanın at, bir kutunun ev, tahta parçalarının şah, parmağın silah olması olabilir. Bu "değil/ karşıt-biçim" olma durumu insan oyununun tamamına genellenebilir. Dolayısıyla oyunun her türü kendi kendisine yaptığı bir "Bu bir oyun" veya "bu gerçek değil" atfını içerir (Myers, 2009, s. 47-48). Nesnelerle oynadığımızda onlar o nesneler, ötekilerle oynadığımızda onlar o ötekiler, kendi kendimize oynadığımızda da kendimiz o kendimiz değil, bir karşıt-kendiliktir. Oynanan nesneler bu karşıt-biçim sayesinde oyuna has nesneler olur. Bu karşıt-biçim/karşıt-kendilik durumları oyunun sihirli çemberi içinde geçerlidir (Myers, 2009, s. 47-48).

Myers'ın bu kavramlaştırmasında oyunların anlatısal yönü oyun deneyimiyle bir zıtlık içindedir. Örneğin, Play Redux: The Form of Computer Games'de Myers (2001) oyunları karşıt-anlatı (anti-narrative) olarak niteler. Ona göre poetik biçim ile bilgisayar oyunu biçimi hem biçimsel hem de duyuşsal olarak farklıdır ve bu fark etkileşimli estetiği supra veya meta-lingual yapmaktadır. Bu nedenle anlatısal biçimler etkileşimli tasarımlarda yer aldıklarında "tutarsız ve sıklıkla disfonksiyoneldirler". Dilin kuralları okuma deneyimini "bağlar, kısıtlar ve motive ederler", oysa oyun deneyiminde böyle bir kısıtlama yoktur. Oyun kuralları uygulanmaya başladığında dilin kuralları oyun sürecine uymak ve gerektiğinde kırılabilmek zorundadır. Dahası oyuncular düzenli olarak oyun kurallarını sınar ve yıkmaya çalışırlar. Kural dışına doğru gerçekleşen bu hareket, oyunun barındırdığı poetik dili anlamsız hale getirir (s. 72-75). 
Myers (2001) ayrıca anlatı ile arka plan öykülerini birbirinden ayırır. Her ne kadar hem anlatılar hem de arka plan öyküler göstergebilimsel süreçlerden ortaya çıksa da arka plan öyküleri bu süreçleri kısıtlamaz veya motive etmez, dolayısıyla anlatılardan oldukça farklı işlevlere sahiptir. Arka plan öyküleri oyun tasarımcıları açısından bir çerçeveleme fonksiyonu yerine getirerek bütün oyun öğelerinin "tutarlı, uygun ve (başarılı bir şekilde) ticari bağlamda" gerçekleştirilmelerini sağlar. Oyuncular için ise arka plan öyküleri daha bencil göstergebilimsel süreçlerin gerçekleşmesini azaltır (s. 87). Bu öykülerin oyunlardaki işlevi diğer ortamlardaki kadar başarıı değildir ve tutarsızdır: "Oyunlardan çıkan göstergebilimsel değer ve çıktılar genellikle anlatılarla birleştirilse de bu anlatılar oyundaki değer ve çıktılara dayatmalardır - oyunun biçim değiştirmeleridir. Yani arka plan öyküleri, değerlerin ve çıktıların oyun sırasındaki üretimine ne sebep olur ne de onu belirler" (Myers, 2001, s. 97).

Bu görüşe göre detaylı anlatıların oyun sırasındaki faydasızlığı ve çoğunlukla önceden belirlenmiş anlatı çerçevelerinin oynanışı olumsuz etkilemesi oyunları algoritmik temelli olmayan kitap, çizgi roman gibi ortamlardan temelde farklı hale getirmektedir. Bu açıdan Myers (2001) insan oyununu geleneksel nedensellik kuramlarının dışında bir "anlatı öncesi eylem" olarak tanımlar. Yenilik üretebilmek için oyun çelişkiye sahip olmalıdır. Dolayısıyla oyunun doğası ve işlevi sıkıca bağlı olduğu insan göstergebilimsel süreçleri gibi "içgüdüsel, söz dinlemez ve bir derece önceden kestirilemezdir" (2001, s. 97).

Jesper Juul (2001) oyunların anlatısal özellikleri olduğunu kabul eder, ancak anlatı olduklarına karşı çıkar. Juul'a göre oyunların anlatı olduğu savını destekleyen üç temel önerme vardır:

1) "Her şey için anlatı kullanırı",

2) "Çoğu oyun anlatısal giriş ve arka plan öyküleri kullanır" ve

3) "Oyunlar anlatılarla bazı özellikleri paylaşırlar." (2001)

Juul bu üç önermeye yanıt olarak oyunların anlatı olmadığını şu gerekçelerle savunur: Öncelikle oyunlar, filmler, romanlar ve tiyatrodan oluşan medya ekolojisine ait değildir. İkincisi oyunlarda zamansallık anlatılarda olduğundan farkı işlemektedir. Üçüncüsü ise okuyucu/izleyici ile öykü dünyası arasındaki ilişki, oyuncu ile oyun dünyası arasındaki ilişkiden farkıı işler (Juul, 2001):

[Ş] una inandığımı yinelemek isterim: 1) Oyuncu bir oyun oturumunun öykülerini anlatabilir. 2) Çoğu bilgisayar oyunu anlatısal öğeler içerir ve çoğu durumda oyuncu oyunu bir sinematik veya bir anlatı sekansını görmek için oynayabilir. 3) Oyunlar ve öyküler bazı yapısal özelliklerini paylaşmaktadır. Yine de vurgulamak istediğim nokta şudur: 1) Oyunlar ve öyküler gerçekte birbirlerine roman ve filmlerdeki gibi iyi uyarlanamazlar. 2) Etkileşimin şimdisi ile anlatının geçmişiveya "daha öncesi" arasında içkin bir çatışma vardır. Anlatım ve etkileşime aynı anda sahip olamazsınız; sürekli etkileşimli öykü diye bir şey yoktur. 3) Okuyucu/öykü ve oyuncu/oyun arasındaki ilişkiler birbirlerinden tamamen farklıdır - oyuncu, 
hem oyunun dışında bir ampirik özne olduğu, ve hem de oyunun içinde bir rol üstlendiği bir alacakaranlık kuşağında ikamet eder.

Espen Aarseth (1997) sibermetin kavramlaştırmasında bilgisayar oyunları ile sınırlı kalmayarak doğrusal olmayan metinlerin hepsinde görülen iki öğeden söz eder. Bu öğelerden ilki bir kafa karışıklığı ve yardıma muhtaçlık hissi olan aporiadır. Hipermetin ile ilk karşılaşmada yaşanan bu his metnin edebi etkisinin dışında bir yabancılaşmadır: Metin bir labirente dönmüştür ve Aarseth seçimler yaparak labirentte daireler çizme deneyimini, Lacan'ı da andırır şekilde, parçalardan yola çıkarak var olduğuna dair hiçbir kanıtın olmadığı bir bütünü yanlış/sahte bir özdeşleşme yoluyla arama çabası olarak betimler. Bu şekliyle aporia, metnin tamamına erişilebilen ancak bir bölümünün anlaşılmaz olduğu edebi aporiadan farklı bir deneyimdir: Hipermetin aporiası metnin bir bölümüne erişemeyişimizden kaynakıı olarak tamamını anlamlandıramamaya dayalıdır (1997, s. 90).

Bu öğelerden ikincisi olan epiphany, bu engellerin ve dolayısıyla aporianın çözümü ile gerçekleşir: Illk bakışta önemsiz bir ayrıntı olan bir öğe, ani, beklenmedik ve kurtarıcı bir etki ile aporianın yerini alır. Ancak bu ani bir aydınlanmadan farklı olarak olumsal değil, akli, planlı bir inşadır. Bu iki öğe arasındaki ilişki, yani "genel olarak oyunlarda tipik olan bir arama ve bulma diyalektiği" hipermetnin temel dinamiğini oluşturur (Aarseth, 1997, s. 90-91).

Fark edilecektir ki Aarseth (1997) ortaya koyduğu bu iki kavram için de terimlerin edebi kuramda kullanılan tanımları arasında sınır çizmeye dikkat etmiştir. Michael Joyce'un (1987) afternoon ${ }^{1}$, a story etkileşimli romanı üzerinden yaptığı bu tartışmada Aarseth bu tür bir metnin anlatıya atıfla pek çok farklı şekilde nitelenebileceğini (isteksiz anlatı, karşıt anlatı, sabote edilmiş anlatı, lineer olmayan anlatı) ancak aslında onun anlatıdan farklı bir şey olduğunu söyler: Bu bir anlatma oyunudur (1997, s. 94).

Burada Aarseth oyunları "etkileşimli anlatılar" olarak gören yaklaşıma oldukça yakın görünmektedir. Aarseth'in bu savını narratoloji kampından kabul edilen Janet Murray'in (1997) Hamlet on Holodeck'te yaptığı çözümlemeyle karşılaştırarak aradaki benzerlik ve farklılıkları anlamak daha kolay olacaktır. Interaktif mecraların öykü anlatımında yapacağı potansiyel devrimi anlattığı bu kitapta Murray (1997) Star Trek dizisinin farklı sezonlarındaki farklı karakterlerin holodeck deneyimlerinden ve bu deneyimlerdeki anlatılardan örnekler verir. Holodeck, Enterprise gemilerinde bulunan ve farklı gerçekliklerin fiziksel olarak deneyimlenebildiği bir uzam, "bireysel olarak programlanmaya açık bir evrensel fantazi makinesidir: bilgisayarın lambadaki bir öykü anlatma cini olduğu bir tahayyülü" (s. 15). Holodeckte dizinin farklı karakterleri boş zaman etkinliği olarak farklı senaryoları deneyimlerler (Murray, 1997). Bu sayede dizi hem öyküde çeşitlilik sağlar hem de izleyiciye karakterlerin farklı yönlerini keşfetme imkânı

1 afternoon isimli romanın isminin ilk harfi küçük yazılmaktadır. 
sunar. Bu sekanslarda Kaptan Jean-Luc Picard film noir senaryolarını tercih etmekte, Kumandan Data Sherlock Holmes'ü oynamakta, Dr. Julian Bashir ise James Bond maceralarını yaşamaktadır. Kaptan Janeway ise Jane Eyre'den esinlenilmiş bir gotik kurgu karakteri olan Lucille Davenport'u seçer. Murray'e göre Kaptan Janeway'in holodeck deneyimleri kendinden öncekilerden bazı yönleriyle ayrımaktadır. Önceki sezonların karakterleri bir bölümde çözülen ve merkezinde çatışma öyküleri olan senaryolar seçerken, Janeway seçtiği kurguyu birçok bölüme yayılmış bir şekilde keşfeder. Janeway'in macerası, çözümlenen doğrusal bir kurgudan çok, açık uçlu ve dünyayı ve karakterleri keşfetmeye dayalı bir anlatıdır ve bu yönleriyle Murray'in "çok biçimli öykü" de dediği etkileşimli öykülere örnektir (1997, s. 15-16).

Murray'in Janeway'in holodeckteki açık uçlu öyküsünü ele alışı, Aarseth'in afternoon'u sibermetin olarak kavramlaştırması ile benzerlik göstermektedir: İki yaklaşımda da öykü öğelerinin doğrusal olarak akmadığı sibernetik deneyimler söz konusudur. Bu yönüyle ele alındığında Aarseth'in çözümlemesi, afternoon ve benzeri metinleri "etkileşimli öykü" veya Murray'in terimiyle "çok biçimli öykü" olarak nitelendirmeye oldukça yaklaşmaktadır, ancak tartışmasında bu metinlerle anlatılar arasında kavramsal bir sınır çizer: Bu mecralarda birbirini izleyen olay dizileri metinsel olsun ya da olmasın bir anlatı değil "başka bir şeydir." Aarseth bu "başka şeyi" ergodik terimiyle niteler (1997, s. 94):

[H]em öyküler hem de futbol maçları birbirini izleyen olaylardan oluşur. Ancak hakkında öyküler anlatılabilse de bir futbol maçının kendisi bir öykü değildir. Oyunun içindeki eylemler anlatısal eylemler değildir. Peki nedirler? Önerdiğim sıfat bir olaylar zincirinin (bir yol, bir eylemler dizisi, vs.) bir veya daha fazla birey veya mekanizmanın azımsanmayacak çabalarıyla üretildiği bir durumu ima eden ergodiktir.

Dolayısıyla oyunlar afternoon gibi tamamen metin temelli olduklarında bile Aarseth'e göre anlatılardan farklı bir kategori oluşturmaktadır. Oyunların sibernetik metinler olarak nitelenmesi Aarseth'i oyunların oyun mekaniği dışında kalan bütün yönlerinin süs olarak alınabileceği (Frasca, 2003, s. 94-95) radikal ludoloji konumundan uzaklaştırır görünmektedir ancak Aarseth'in yaklaşımında vurgu her zaman oyunun kendine has ergodik yönü üzerindedir. Örneğin Genre Trouble: Narrativism and the Art of Simulation isimli kitap bölümünde Aarseth (2004), narrrativist ve görselci iddiaların aksine, oyundan alınan hazzın kinestetik, fonksiyonel ve bilişsel olduğunu savunur (s. 52). Ona göre her ne kadar film incelemeleri Lara Croft'un bedenini bıkıp usanmadan analiz etmiş olsa da, farklı bir avatar ile oyuncu oyunu farklı şekilde oynamayacaktır çünkü oyuncu ekrandaki bedeni görmez bile (s. 48). Markku Eskelinen (2001) de benzer şekilde The Gaming Situation'da oyunların ve oyun durumunun öykü, anlatı ve sinemadan ayrı tutulması gerektiğini söyler. Ona göre öyküler oyunlar için "ilginç olmaktan uzak süsler ya da hediye paketleridir ve bu tür pazarlama araçlarının çalışılması bir zaman ve enerji israfıdır". Eskelinen'e (2001) göre oyunları etkileşimli anlatı ya da sinema olarak ele almak araştırma destekleri elde etmede başarılı olsa da 
kavramsal olarak zayıf temellerdir ve bu tür bir yaklaşım "20. yüzyıl ile her tür entelektüel teması es geçme çabası" ve kuramsal bir "suikast" olmakla kalmaz, uzun vadede ticari oyunlar açısından kötü sonuçlar doğurma ihtimali de barındırır.

\section{Ludoloji'ye Eleştiriler}

Ludoloji oyun çalışmalarını edebi kuram, sinema kuramı, görsel incelemeler ve dramaturji gibi yerleşmiş disiplinleri korumak için verdiği mücadeleyi oyunları bu disiplinlerin nesnelerinden ontolojik olarak ayırarak temellendirir. Bu duruş hem ontolojik varsayımları ve buna bağlı geliştirdiği kuramsal araçların yetersizliği, hem de bu yetersizliğe çare olabilecek farklı yaklaşımları alanda marjinalize etmesi nedeniyle eleştiriler almıştır. Bu iki yönü de kapsayan bir eleştiriye örnek olarak Kevin Moberly'nin (2013) Preemptive Strikes: Ludology, Narratology, and Deterrence in Computer Game Studies başlıklı kitap bölümü verilebilir. Moberly bu çalışmasında ludolojinin oyunları sadece oyun olarak ele alan yaklaşımının "ayrımlar ve karşı ayrımlar, nitelemeler ve karşı nitelemelerden oluşan, değişmez şekilde karmaşık bir analitik sistem" ortaya koyduğunu söyler (s. 166). Moberly'ye göre ludolojinin biçimsel analiz için kavram arayışları bazı oyunların sıra tabanlı olup diğerlerinin olmadığını söylemek için bile paragraflar süren analizlere neden olmakta, en bildik oyunun çözümlemesini bile içinden çıkılmaz hale getirmektedir. Dahası ludolojistler "oyun olarak oyun"u koruma çabaları nedeniyle bu biçimsel analiz yaklaşımına tehdit olarak gördükleri her şeye karşı savunma halindedirler. Öyle ki, Moberly'nin deyişiyle ludolojistler "Laura Croft'un [sic] kayda değer çekiciliğine bile" dayanıklıdırlar (s. 167).

Janet H. Murray (2005) benzer bir eleştiriyi DIGRA 2005'te yaptığı The Last Word on Ludology v Narratology in Game Studies başlıklı açılış konuşmasında yapar. Murray'in oyun özcüleri adını verdiği ludolojistler, biçimsel yaklaşımlara ayrıcalık tanımak istediklerinden oyun deneyiminin "sürükleyicilik hissi, şiddet içeren veya cinsel olayların sahnelenmesi, oynanışın performatif boyutu ve hatta kişisel kazanma kaybetme deneyimi" gibi önemli yönlerini göz ardı etmeye hazırdırlar. Bu anlayışa göre oyunları çalışan bir araştırmacının duygusal, anlatısal ve simgesel açıdan oldukça yüklü nesnelere bakıp sadece "soyut oyun işlevleri" görebilen bir kış ruhuna sahip olması gerekir.

Bu biçim odağı Bogost (2009) tarafından da eleştirilmiştir. Narratolojinin temellerinin de Rus biçimcilere dayandığını hatırlarsak, ludoloji ve narratoloji tartışması aslında, "oyun nedir?" sorusuna verilen yanıt üzerinden şekillenmiş olan iki rakip biçimcilik arasındaki bir tartışmadır. Bogost, DIGRA 2009'da yaptığı Videogames are a Mess başıkılı açıış konuşmasında şöyle der:

Gerçekten hangisinin kazandığı önemli değil, çünkü [ludoloji ve narratolojinin] altındaki ön kabuller çok benziyor. Ludoloji/narratoloji meselesi şöyle görünmüş olabilir: 


\begin{abstract}
"Bir oyun bir kurallar sistemi midir, yoksa bir oyun bir tür anlatı mıdır?" Oysa gerçekte, daha çok böyle bir şeydir:

"Bir oyun, bir öykünün bir anlatım sistemi olmasına benzer şekilde bir kurallar sistemi midir?" (Bogost, 2009)
\end{abstract}

Bogost'a göre bir biçimciliği diğerinin karşısına bu şekilde koyduğunuzda sonuç kaçınılmazdır: "Biçimcilik kazanır!" (Bogost, 2009). Bogost, soru ikinci şekilde sorulduğunda yanıın "evet" olacağını söyleyerek ludolojiye yakın durduğunun sinyalini verir, ancak ona göre gerçekte "oyun nedir" sorusunun alandaki merkeziyeti problemlidir. Bogost'a göre bu stratejik, retorik veya siyasi değil ontolojik bir sorudur ve "bir metafizik meselesidir, alan inşa etme meselesi değil" (2009).

Bu ontoloji merkezli biçimcilikler çarpışması oyun çalışmaları alanının da sınırlarını çizmekte ve bunun sonucu olarak bu iki taraf, iki ontoloji ve iki biçimsel analizin dışında kalan yaklaşımları öteki haline getirmektedir. Kevin Moberly'ye (2013) göre "bu kutuplar ikili bir işlev yerine getirirler, sadece oyun çalışmalarını neyin oluşturduğunun dış sınırlarını çizmekle kalmaz, aynı zamanda Aarseth'i, Eskelinen'i ve diğer ludolojistleri söylemin merkezine yerleştirirler [...] Sonuç, sınırları dikkatle çizilmiş yarışmacıların olduğu, sınırları dikkatle çizilmiş bir alandır" (s. 163).

Buna rağmen ludoloji oyunların diğer disiplinler tarafından incelenmesine kapıyı kapatmaz. Örneğin Espen Aarseth (2006) oyun çalışmalarının disipliner sınırlarını tartıştığı How We Became Postdigital: From CyberStudies to Game Studies başlıklı kitap bölümünde, oyunların çok sayıda disiplinin ilgi alanına girebileceğini savunur. Aarseth'e göre dijital oyunların ilgi alanına girdiği alanlar arasında oyun teorisi (game theory), oyun araştırması (play research), oyun ve simülasyon, masa oyunu çalışmaları ve spor felsefesi bulunmaktadır. Sorun bu alanların birbirlerinden kopukluğu ve hiçbirinin özellikle oyunlarla ilgilenmemesidir, bu nedenle "oyun çalışmaları" adında bir alana intiyaç duyulmaktadır. Aarseth oyun çalışmalarının bileşenleri ve beslenebileceği metodolojik ve disipliner yaklaşımlar arasında sosyoloji, etnoloji, psikoloji, pedagoji, oyun tasarımı, ekonomi, bilgisayar bilimi/yapay zekâ, sanat, estetik, tarih, kültürel/medya çalışmaları ve hukuku sayar. Yeni bir interdisipline duyulan intiyaca yaptığı vurgu ile ludolojinin oyun çalışmalarının mevcut disiplinlerin yönetiminden bağımsız, ancak onlardan beslenen bir araştırma alanı olarak kurulmasını önerir (s. 43). Ancak oyun incelemelerini diğer disiplinlerin eline bırakmamak gerektiğini de belirterek ludolojinin merkezde olması gerektiğini vurgular. Aarseth'in (2001) sözleriyle, oyunlar "elbette ki medya çalışmaları, sosyoloji ve İngilizce gibi mevcut alan ve bölümlerde de incelenmelidir. Ancak oyunlar bu alanlara bırakılamayacak kadar önemlidir. (Ve hiçbir şey yapmamış oldukları otuz yıl zamanları vardı!)". 
Başka bir yazısında Aarseth (2004) diğer disiplinlerin oyunlara olan ilgisini bir 'altına hücum'a benzetmektedir. Edebiyat veya film incelemeleri gibi komşu disiplinler "fırsat ve macera dolu altın topraklarda yeni bir başlangı̨̧ yapma şansına hevesle sarılmaktadır2" (s. 45). Bu hücumda, benzerlerinde olduğu gibi "yerel kültür ve tarihe saygı minimaldir" ve kültürel ve metinsel incelemeler gibi disiplinler "kendi gelenek, araç ve becerilerine" tam bir inançla "bakir topraklar" olan oyun çalışmalarını parseller, kazar, ekip biçer (s. 45).

Kurulu disiplinlerin kavramsal araçlarına saplanmadan oyunların kendine has yönlerine uygun kavramsal araçlar geliştirilmesi sürekli dönüşen ve ilerleyen bu ortamın incelenmesinde büyük öneme sahiptir. Burada esas sorun ludolojinin oyunlara oyun olarak yaklaşabilmek için geliştirdiği biçimselci araçların bu mecrayı incelemede karşılarında alanı korumaya çalıştığı "sömürgeci" disiplinlerin araçları kadar yetersiz oluşudur. Eskelinen (2001) ve zaman zaman Aarseth'in (2004) bu biçimsel yaklaşımları merkeze koymaları oyun çalışmalarını Murray'in (2005) oyun özcülüğü adını verdiği uç noktaya taşımakta, oyunun başat biçimi olarak gördükleri gameplay dışındaki metinsel/kültürel öğelerin önemsiz süsler olarak kenara atılmasına neden olmaktadır.

Oyunların metinsel/kültürel yönlerini göz ardı eden bu konum Türkiye'deki araştırmacılardan da önemli eleştiriler almıştır. Bunlara bir örnek i. Altuğ Işığan'ın (2012) Etkileşimsellik Sorunu Çerçevesinde Dijital Oyun-Anlatı Ilişkisi başlıklı doktora tezidir. Işığan bu çalışmada Barthes'ın mitik söylem tanımını izleyerek oyunların içerdikleri birincil göstergelere eklenen ikincil gösterge dizgeleri ile anlamlandıklarını savunur (s. 118-120). Oyunlar kazandıkları bu anlam nedeniyle anlamı sorunsallaştıran disiplinlerin, dolayısıyla da dilbilim, anlatı ve söylem kuramlarının alanına girer (s. 127). Işığan'a göre başta yapısalcı kuramlar olmak üzere dille ilgili kuramların oyun çalışmalarına geri kazandıııması oyun araştırmalarının kullanmakta olduğu kuramları güçlendirmekle kalmayıp yapısalcı ve postyapısalcı düşünceyi de dönüştürecektir (s. 272-273).

Anlatıların oyunlarla ilişkisinin göz ardı edilemeyecek kadar karmaşık olduğunu gösteren çalışmalara bir diğer örnek Özge Sayılgan (2014) Etkileşimli Drama Olarak Dijital Oyunlar ve 'Etkileşimliliğin Ideolojisi' Bağlamında Oyuncu Alımlama Pratikleri isimli doktora tezidir. Sayılgan bu çalışmada oyunlarda etkileşimlilik ve anlatı ilişkisine kültürel kodlama, kod açımı ve alımlama kavramları üzerinden yaklaşmaktadır. Sayılgan'a göre öyküye sahip dijital oyunlarda kodlanmış egemen okuma ve oynama biçimleri bulunmasına rağmen oyuncuların bu biçimleri kırarak daha eleştirel biçimler geliştirebildiği sonucuna varmaktadır. Bu okuma ve oynama biçimleri birbirlerinden bağımsız olarak geliştirilebilmektedir. Örneğin oyunun anlatısını eleştirel bir biçimde okuyan bir oyuncu egemen oynama biçimini izleyebileceği gibi farklı, muhalif oynama pratikleri geliştirebilmektedir (s. 557-558). Bu bulgular radikal ludolojist konumun

2 Burada Aarseth, Blade Runner (Scott, 2982) filminde geçen bir cümleye atıfta bulunmaktadır. 
anlatının önemsiz bir süs olduğu yönündeki iddiasını çürütmekle kalmaz, Işığan'ın (2012, s. 272-273) önerisini de destekler biçimde, dil ve anlatının oyunlardaki rolünün karmaşıkığını da gözler önüne serer.

Ludolojiye yapılan eleştirilerin ve oyunlarda anlatının önemini ortaya koyan bu çalışmaların da gösterdiği gibi dil ve anlatının oyunlardaki rolü karmaşık ve oyunları anlamak açısından önemlidir. Oynanış biçimlerini metinsel, görsel, işitsel içerik ve kültürel bağlamı göz ardı etme derecesine kadar fetişleştirmesinin yanında oyunları incelemek için geliştirdiği kavramsal araçların da aşııı karmaşık ve yetersiz oluşu, ludolojinin önerdiği yaklaşımın oyun çalışmaları için sağlam bir temel oluşturmaktan uzak olduğuna işaret eder. Bogost'un (2009) da dediği gibi, metafizik bir varsayım ile temellenmiş bir biçimcilik alan inşası için yeterli bir başlangıç noktası değildir. Oyun çalışmaları görsel incelemelerin imgeler için yaptığına benzer şekilde oyunların tarihini, kültürel bağlamlarını ve içeriklerini paranteze almayan kuramsal temeller atmadığı sürece alanını "sömürgeci" disiplinlerden korumakta zorlanacaktır.

\section{Biçimler ve Anlatıların Ötesinde: Prosedürel Retorik ve Algoritmik Kültür}

Her ne kadar ludoloji-narratoloji tartışmasına yapılan atıflar birbirinden bıçakla kesilmiş gibi ayrıksı ve sınıları belirgin bir disipliner bölünmeyi ima etse de, gerçekte bu iki yaklaşımın çok sayıda ortak noktası vardır. Her iki gruptan da yazarlar oyunların ontolojisine, kurama ve yönteme dair aşırı derecede basite indirgenmiş temsillerden ve gerçekte var olmayan bir tartışma izlenimi yaratıldığından yakınır (Murray, 2005; Frasca, 2003). Tartışma karşıt konumların karikatüristik derecede indirgemeci temsillerinin yanı sıra daha önemli bir ön kabulü de pekiştirmektedir: oyunların incelenmesinde oyunun anlatı mı yoksa oyun mu olduğunun ve narratolojik veya ludolojik biçimlerin incelenmesinin merkezi derecede önemli olduğu kabulü. Ancak Bogost'un (2009) da dediği gibi tartışmanın taraflarının oyunların ontolojisine verdiği öneme rağmen "oyun nedir" sorusunun cevabı çevresine alan inşa edilecek sağlam bir temel olmaktan uzaktır.

Bu bölümde ludoloji ve narratoloji arasındaki ontoloji ve biçim tartışmalarının dışına çıkma yönünde bir adım olarak görülebilecek yaklaşımlar olan lan Bogost'un prosedürel retorik ve Alexander R. Galloway'in algoritmik kültür kuramlarına yer verilecektir. İsimlerinden anlaşılacağı gibi bu iki yaklaşım oyunların algoritmik ve göstergebilimsel/kültürel/anlatısal yönlerini birlikte ele alan kavramlar formüle etmişlerdir.

Bogost (2006) oyunların çalışıldığı literatürde sıkça atıfta bulunulan prosedürel retoriği kavramlaştırdığı kitabı Unit Operations'ıçok da iyi geçinemeyen iki alan olan 'edebi kuram ve felsefe' ile 'yazılım teknolojisi ve video oyunu tasarımı' alanları arasında bir uzlaşma sürecinin ürünü olarak tanımlar (s. vii). Bogost'a göre bilişimsel metinleri çalışan beşeri bilimcilerin teknolojiyi ciddiye alması, 
teknologların da kullandıkları yazılım teknolojisine eşlik eden ve bu teknolojilerde izi sürülebilecek eleştirel, felsefi ve edebi yaklaşımları anlaması gerekmektedir (s. ix). Buradan yola çıkan Bogost, karşılaştırmalı bir yaklaşım kullanarak güncel edebi analiz ile bilgisayar biliminin benzer prensiplere dayandığını öne sürer ve bu savının merkezindeki kesişimi dünyada henüz yerini bulamamış bir söylemsel üretim alanı olarak nitelendirdiği video oyunlarının analizinde kullanır (s. ix).

Bogost'un (2006) bu karşılaştırmalı yaklaşımından ortaya çıkan ve uzlaştırma çabasının merkezine koyduğu kavram birimdir. Bogost'a göre "poetik, edebi, sinematik, ve bilişimsel" her ortam birbirinden ayrıksı ancak birbirine kenetlenmiş bir şekilde düzenlenmiş 'ifadesel anlam (expressive meaning) birimleridir' (s. ix, vurgu eklenmiştir; s. 45). Bogost birim terimini oyunlarla ilgili birçok alanla ilişkili düşünülebilecek olmasına rağmen hiçbirine ait olmayan bir sözcük olarak seçmiştir:

Bir birim, özünde, materyal bir öğe, bir şeydir. Zorunlu ya da olumsal olabilir, bir sistemi oluşturan bir tuğla gibi; ya da otonom olabilir, bir sistemin kendisi gibi. Çoğunlukla, sistemler başka sistemlerin içinde birim olurlar. Yazılım sınıfları, çok sayıda yazılım çerçevesinde başlayabilen bilgisayarsal davranış modelleridir ve yazılım çerçeveleri çok sayıda yazılım uygulaması halinde birleşebilir. [...] Nesne ve özellikle nesne-yönelimli terimlerinden kaçınıyorum çünkü [...] bu kavramlar bilgisayar biliminde özel anlama sahiptir. (2006, s. 5)

Bogost'un yazılım teknolojisi, fizik ve sibernetikten olduğu kadar edebi kuramdan da faydalanan birim kavramı üzerine inşa ettiği birim işlemi (unit operation), bu tür ifadesel birimleri içeren prosedürel/algoritmik işlem anlamına gelmektedir (2006, s. 1). Bu çerçeve üzerinden Bogost prosedürel retorik kavramını oluşturur. Plato ve Aristoteles'e dayanan bir retorik tanımı üzerinden ulaştığı bu kavramlaştırma 'etkili ve ikna edici bir ifade'ye karşılık gelir (2007, s. 3; 2007, s. 18). Prosedürelliğin ve birimlerin ayırt edici özelliği ikna gücüdür: "Süreçler bizi etkiler. Tutumlarımıza değişim tohumları ekerler ki bunlar zaman içinde kültürümüze dönüşür" (2007, s. 340).

Prosedürel retorik kavramlaştırması oyunlara dair çalışmalarda yaygın olarak kullanılmaktadır, öyle ki Miguel Sicart (2011) Against Procedurality makalesinde prosedürelliği ludoloji benzeri bir okul olarak tanımlar. Gerçekten de "prosedürellik", " ifade edici birimler" ve ilişkili kavramlar aralarında sanat oyunları, estetik, ses, oyunların sağlık kampanyalarında kullanımı, feminist pedagoji ve ciddi oyunlar gibi çok çeşitli konulara sahip çalışmalarda sıklıkla karşımıza çıkar (Allen, 2014; Oldenburg, 2013; Teli, Paoli ve Maiolini, 2012; Vella, 2015).

Ancak Bogost'un kavramlaştırması eleştirilere de maruz kalmıştır. Miguel Sicart (2011) bu yaklaşımı "oyun çalışmaları ve oyun tasarımı alanlarındaki etki ve uygulamaları" açısından kusurlu ve sorgulanmaya açık olarak nitelendirir. Sicart'a (2011) göre prosedürel retorik, "iddialarını destekleyecek ampirik veri eksikliği, kendi tasarım çalışmalarını sunmada eleştirel düşünce eksikliği" gibi sorunlarının 
yanında incelediği oyunların seçimi ve "oyuncu ve oyun" konusunda önemli bir ilgi eksikliğine sahiptir. Calum Matheson (2015) ise kuramı retorik kavramını Aristoteles ve Plato'nun formülasyonu ile kullanmakla yetinerek kavrama yapılan başta Lacancı olmak üzere sayısız müdahaleyi dikkate almamakla eleştirir. Matheson'un da belirttiği gibi, prosedürel retorik ile "çok sayıda yol açılmıştır ancak bunlardan bir tanesi diğerlerinden daha ağır bir şekilde çiğnenmiştir" (2015, s. 465-466). Bu keşfedilmemiş yollara örnek olarak Veli-Matti Karhulahti'nin (2013) Bogost'un retoriği iddia ve argüman temelli kavramlaştırmasına alternatif olarak ve mecranın etkileşimliliğine daha uygun biçimde, oyunları performans temelli bir ikna süreci olarak ele alması verilebilir. Bunların yanında Jan Švelch'e (2016) göre Bogost oyuncu kültürlerinden çok oyunlara ve mekaniklere vurgu yaparak oyunların bilişimsel yönüne ayrıcalık tanımaktadır. Švelch (2016), kültürü bir kenara bırakarak dijitali ön plana çıkaran bu eğilimi bilişimsel özcülük olarak adlandııı ve tartışma odağının oyun mekaniklerinden oyunlara geri çekilmesi yönünde bir çağrıda bulunur.

Oyunları anlatı veya oynanış biçimlerine indirgemeden ele alan yaklaşımlara bir diğer örnek Alexander R. Galloway'in (2006) algoritmik kültür kavramlaştırmasıdır. Edebi kuram ve yazııımsal prosedürler arasında Bogost'un (2006) Unit Operations'una benzer bir uzlașma çabası olarak görebileceğimiz Gaming: Essays on Algorithmic Culture isimli kitabında Galloway (2006) oyunları ve oyunu (gaming) organik ve inorganik makinelerden oluşan sibernetik bir toplam olarak ele alır (s. 2). Galloway (2006) oyunu oyun yapan öğelerin eylemler olduğunu savunur. Görüntüler fotoğraflar için, hareketli görüntüler filmler için neyse eylemler de video oyunları için odur (s. 2): "Eylem olmadan oyunlar sadece soyut bir kurallar kitabında kalırlar. Oyuncuların ve makinelerin aktif katıımı olmadan video oyunları sadece statik bilgisayar kodu olarak var olur. Video oyunları makine çalıştırılıp yazııı başlatıldığında [...]; eylendiklerinde var olurlar" (2006, s. 2).

Galloway'e (2006) göre film veya fotoğraf gibi ortamlarda o ortamı meydana getiren eylemler üretimden önce gerçekleşmekte ve ortam fiziksel bir obje biçiminde ortaya çıkmaktadır. Video oyunlarında ise oyuncu oyunu oynamakta, yazılım çalışmakta, "operatör ve makine oyunu birlikte, adım adım, hamle hamle oynamaktadır" (s. 2). Oyunun içerdiği bu eylem temelli sibernetik döngü onu fotoğraf ve film gibi ortamların yanı sıra geleneksel oyunlardan da ayırır. Oyunların temelinde kod bulunması onları oyun olmanın yanı sıra yazılım sistemleri yapmaktadır ve bu analizlerde en ön planda tutulmalıdır. Diğer bir deyişle, video oyunları veritabanları ile satranç veya bilardo ile olduğundan daha fazla ortak yöne sahiptir. Dolayısıyla dijital oyunlar algoritmik kültürel nesneler olarak ele alınmalıdırlar (s. 6).

Oyunun enformatik yönüne yapılan bu vurgunun Galloway'in (2006) oyunun merkezine koyduğu eylem açısından bir doğurgusu eylemin makine ya da operatör eylemi olabileceğidir. Galloway bu iki eylem türünü sadece "yapay" olarak ayırdığını belirtir; operatör ile makine arasındaki sibernetik ilişki nedeniyle 
makine ve kullanıc eylemi ontolojik olarak farksızdır (s. 5). İkinci ayrım ise eylemin diejetik veya diejetik olmayan uzamlarda gerçekleşebilmesidir. Galloway'in film kuramından aldığı bu terimleri kullanımında diejetik eylemler ilişkili oldukları uzamın ekranda görünür olup olmadığından bağımsız olarak oyunun anlatısıyla ilişkili olan eylemlerdir. Diejetik olmayan eylemler ise oyun dünyası, karakter ve öyküyle merkezi bir bağı olmayan eylemlerdir. Örneğin karakterlerin oyun dünyasındaki hareketi diejetik bir eylem iken, oyunun dondurulması diejetik olmayan bir eylemdir (s. 7-8). Oyunu oluşturan bütün eylemler bu iki eksen (makine-operatör, diejetik-diejetik olmayan) üzerine düşerler. Örneğin JRPG türü oyunlardaki oldukça detaylı karakter yönetimi ekranları diejetik olmayan operatör eylemleri iken Shenmue'da (Suzuki, 1999) operatör uzun süre eylemsiz kaldığında oyun dünyasının belli bir denge durumuna düşüp ilerlemeye devam etmesi diejetik makine eylemine örnektir (s. 10, s. 16).

Şekil 1. Oyunsal eylemler (gamic acts)

(Kaynak: Galloway 2006, s. 17)

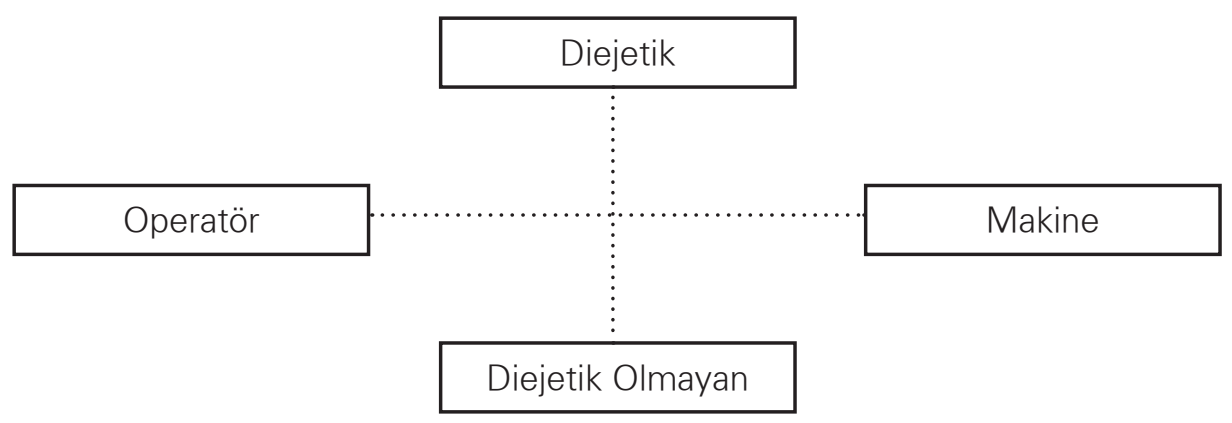

Göstergelerin ve eylemlerin bir algoritma içinde düşünüldüğü bu yaklaşım narratolojinin ve ludolojinin anlatı ve etkileşimi neredeyse bir zıtlık içinde gören kavramlaştırmalarını ve önerdikleri biçimsel incelemenin sınırlılıklarını aşan bir çerçeve sunmakla kalmaz; oyuncu ve makine arasındaki oynanış eylemlerinden oluşan geribildirim döngüsünü ön plana almasıyla oyunları oyuncu ve makineden oluşan insan sonrası sistemler olarak görmenin de kapısını aralar. Bu şekilde oyunun biçimsel özelliklerinin analizinin ötesine geçilerek oyun öğeleri aktörler olarak görülebilir. Dolayısıyla bu tür bir kavramlaştırma kültür/anlatı/göstergebilim ve etkileşimlilik ile olduğu kadar bilim - teknoloji çalışmaları, insan sonrası kuramları ve Aktör Ağ Teorisi ile de diyaloga açıktır.

Burada ilginç olan nokta Aarseth'in (1997) sibermetin kavramlaştırmasının da sibernetik/insan sonrası bir metin varsayımından yola çıkmasıdır. Aarseth Cybertext'te hem N. Katherine Hayles'in insan sonrası tanımını hem de Galloway'in algoritmik kültür kavramını hatırlatır biçimde sibermetni gösterge, ortam ve insanı içeren bir makine olarak tanımlar (Aarseth, 1997, s. 21; Galloway, 
2006, s. 17; Hayles, 1999, s. 29-33). Ancak Aarseth (1997) sibermetinleri anlatıdan ayıran sınırı çizmek için onları ergodik yazın olarak tanımlama sürecinde oyuna has özelliklere yaptığı vurgu ile kavramının merkezine algoritmik özellikler yerine oyunsal özellikleri yerleştirir. Yukarıda değinildiği gibi Galloway'e (2006) göre dijital oyunlar bilardo veya satrançtan çok veri tabanları ile ortak yönlere sahiptir, bu nedenle algoritmik kültür olarak ele alınmalıdır (s. 6). Aarseth'e (1997) göre ise dijital oyunlar, futbol maçları gibi birbirini izleyen olaylara sahiptir. Bu olayları bir veya birden fazla mekanizma (insan ya da insan olmayan) üretir. Bu nedenle dijital oyunlar ve hipermetinler aynı futbol maçları gibi ergodiktir (s. 94). Bu şekilde ludolojinin kuruluşunda vurgu dijital oyunların sibernetik ve insan sonrası özelliklerinden çok birbirini izleyen olaylara yapılır ve bir point and click macera oyunu ile bir satranç oyunu aynı kavramlar kullanılarak (örneğin aporia ve epiphany) incelenebilir hale gelir. Dolayısıyla, ludoloji her ne kadar zaman zaman oyunları sibernetik makineler olarak tanımlasa da "oyun olarak oyunu" merkeze koyma çabası nedeniyle kavramsallaştırmalarının odağına ağırlıklı olarak oyunlara has biçimleri almak zorunda kalmış, biçimci ve kimilerine göre özcü (Murray, 2005) kavramları ön plana alarak oyunların algoritmik ve kültürel yönlerini göz ardı etmiştir.

Bogost (2006; 2007) ile Galloway'in (2006) yaklaşımları oyunları prosedürel/algoritmik kültürel süreçler olarak inceleme amaçlı araç kümeleri sunmaları açısından birbirlerine benzer görünseler de kullandıkları birimler ve odaklar açısından aralarında farklııklar bulunmaktadır. Öncelikle Bogost yukarıda değinildiği gibi analizinin merkezine ifadesel anlam birimlerini koyarken (2006, s. 3), Galloway oyunun temel biriminin eylem olduğunu savunmaktadır (2006, s. 2). Bogost (2006) sistem ve birimleri bir ikili zıtlık içinde düşünmese de kuramında birimlere vurgu yapar. Sistemler sadece başka sistemlerin birimleri oldukları zaman Bogost'un ilgi alanına girer (s. 3-5). Farklı vurgularına rağmen Galloway ve Bogost'un yaklaşımları oyunların ne olduğu sorusunun ve biçimsel özelliklerinin alandaki merkeziyetini sorgulayıcı kavramlaştırmalar içermektedir. İki kuram da oyunları bir anlatı-oynanış dikotomisi içinde görmeye zemin hazırlamış bir tartışmaya taraf olmaya güçlü alternatifler sunmakta ve bu nedenle de oyun çalışmaları alanı için büyük önem taşımaktadır.

\section{Sonuç}

Bu çalışma oyun incelemeleri alanında uzun süre ön planda kalmış olan narratoloji- ludoloji tartışmasını eleştirel bir şekilde ele alarak içerdiği kavramsal ve yöntemsel çıkmazları tartışmayı amaçlamıştır. Bu amaçla tartışmanın taraflarını ve eleştirilerini ele alan alanyazın taranmış, bu taramaya dayalı olarak narratoloji ve ludolojinin ontolojik varsayımları, etkilendikleri kuramlar ve oyunların incelenmesi için sundukları kavramsal araçlar eleştirel bir şekilde karşılaştııılmıştır.

Ludoloji oyunların etkileşimli anlatılar olarak ele alınabileceğine karşı çıkarak oyunların oyun olarak incelenmesi gerektiğini savunmuş, bu ontolojik varsayıma 
dayalı olarak oyunların biçimsel analizinde kullanılmak üzere kendi kavramlarını geliştirmiştir. Ludolojinin bu hamlesi farklı bir ontolojik varsayımdan hareket etmesine ve farklı kavramlar kullanmasına rağmen oyunların incelenmesini yine biçimler üzerinden yapması nedeniyle eleştirilmiştir (Bogost, 2009). Ayrıca narratoloji ve ludoloji tartışması bu iki biçimcilik dışında kalan ve özellikle kültürü ve politik ekonomiyi denkleme sokan yaklaşımları alanda ötekileştirmiştir (Moberly, 2013, s. 163).

Her ne kadar tartışmanın önemli isimlerinden bazıları bu tartışmanın bittiğini ya da hiç yaşanmamış olduğunu iddia etse de (Frasca, 2003; Murray, 2005), Işığan (2012) ve Sayılgan'ın (2014) çalışmalarının da gösterdiği gibi dil, anlatı ve genel olarak kültürün etkileşimlilik bağlamında nasıl ele alınacağı alanda önemini koruyan bir sorunsaldır. Dijital oyunlar son derece karmaşık kültürel ürünlerdir. Dolayısıyla oyunların incelenmesinde içerikleri, içinde üretildikleri kültürel matris, üretim ilişkileri, oynanış biçimleri kadar büyük öneme sahiptir. Bunun yanında Galloway'in (2006) de belirttiği gibi dijital oyunlar algoritmiktir (s. 6), bu nedenle bir spor müsabakası veya labirent gibi dijital olmayan oyunlarla ortak özelliklerine rağmen enformatik yönleri de incelenmelerinde göz önünde tutulmalıdır.

Oyunların bu çok yönlülüğü gerek oynanışsal gerek dilbilimsel başat biçimlere odaklanan kavramsal çerçevelerin ötesine geçilmesini gerektirmektedir. Bogost'un (2006; 2007) ve Galloway'in (2006) sunduğu kavramlaştırmalar oyunların bu çok yönlü yapısını dikkate alma yönünde önemli bir adımı temsil etmektedir. Bu kuramlar oyun çalışmalarının ontoloji ve biçime odaklı tartışmaların kıskacından çıkması ve diğer disiplinlerin alana hâkimiyet kurmasından endişe etmeden kültürel incelemeler, görsel incelemeler, eleştirel kuram ve bilişimin kavramsal birikimlerinden faydalanabilmesi açısından değerli başlangıç noktalarıdır.

\section{Kaynakça}

Aarseth, E. J. (1997). Cybertext: Perspectives on Ergodic Literature. Baltimore, Londra: John Hopkins University Press.

Aarseth, E. (2001). Computer Game Studies, Year One. Game Studies, 1(1), Temmuz 2001. Erişim 15 Nisan 2017, http://gamestudies.org/0101/editorial.html

Aarseth, E. (2004). Genre Trouble: Narrativism and the Art of Simulation. N. Wardrip-Fruin, P. Harrigan, (Ed.), First Person: New Media as Story, Performance, and Game içinde (45-55). Cambridge: The MIT Press.

Aarseth, E. (2006). How We Became Postdigital: From Cyberculture Studies to Game Studies. D. Silver ve A. Massanari, (Ed.), Critical Cyberculture Studies içinde (37-46). New York, Londra: New York University Press.

Allen, S. (2014). Video Games as Feminist Pedagogy. Loading..., 8(13). Erişim 10 Nisan 2016, http://journals.sfu.ca/loading/index.php/loading/article/view/135 
Bogost, I. (2006). Unit Operations: An Approach to Videogame Criticism. Cambridge, Londra: The MIT Press.

Bogost, I. (2007). Persuasive Games: The Expressive Power of Videogames. Cambridge, Londra: The MIT Press.

Bogost, I. (2009). Videogames are a Mess. DIGRA 2009 açılış konuşması. Erişim 15 Nisan 2017, http:// http://bogost.com/writing/videogames_are_a_mess/

Coward, R. ve Ellis, J. (1977). Language and Materialism: Developments in Semiology and the Theory of the Subject. Londra: Routledge \& Kegan Paul.

Eskelinen, M. (2001). The Gaming Situation. Game Studies, 1(1). Erişim 15 Ekim 2017, http://www.gamestudies.org/0101/eskelinen/

Frasca, G. (2003). Ludologists Love Stories, Too: Notes from a Debate That Never Took Place. DIGRA 2003 tebliği. Erişim 10 Nisan 2017, http://www.digra. org/digital-library/publications/ludologists-love-stories-too-notes-from-a-debatethat-never-took-place/

Galloway, A. R. (2006). Gaming: Essays On Algorithmic Culture. Minneapolis, Londra: University of Minnesota Press.

Harris, R. ve Taylor, H. (2005). Landmarks in Linguistic Thought I: The Western Tradition from Socrates to Saussure (2. baskı). London, New York: Routledge.

Hayles, N. K. (1999). How We Became Posthuman: Virtual Bodies in Cybernetics, Literature, and Informatics. Chicago, London: University of Chicago Press.

Herman, D. (2009). Basic Elements of Narrative. West Sussex: Wiley-Blackwell.

Hyvärinen, M. (2006). Towards a Conceptual History of Narrative. M. Hyvärinen. A. Korhonen, ve J. Mykkänen (Ed.), The Travelling Concept of Narrative içinde (20-41). Helsinki: Helsinki Collegium for Advanced Studies.

Işığan, I. A. (2012). Etkileşimsellik Sorunu Çerçevesinde Dijital Oyun-Anlatı iliş̧kisi. Yayınlanmamış doktora tezi, Ankara Üniversitesi.

Jenkins, H. (2004). Game Design As Narrative Architecture. N. Wardrip-Fruin ve P. Harrigan (Ed.) First Person: New Media as Story, Performance, and Game içinde (118-130). Cambridge, MA: The MIT Press.

Juul, J. (2001). Games Telling stories? - A brief note on games and narratives. Game Studies, 1, (1). Erişim 10 Nisan 2016, http://www.gamestudies.org/0101/ juul-gts/

Joyce, M. (1987). afternoon, a story. Watertown, MA: Eastgate [Oyun].

Karhulahti, V. (2013). A Kinesthetic Theory of Videogames: Time-Critical Challenge and Aporetic Rhematic. Game Studies, 13(1). Erişim 10 Nisan 2016, http:// gamestudies.org/1301/articles/karhulahti_kinesthetic_theory_of_the_videogame 
Lankoski, P. ve Björk, S. (2015). Formal analysis of gameplay. P. Lankoski ve S. Björk (Ed). Game Research Methods: An Overview içinde (23-36). Erişim 10 Mayıs 2017, http://press.etc.cmu.edu/content/game-research-methodsoverview

Laurel, B. (1991). Computers as Theatre. Menlo Park, CA: Addison-Wesley.

Matheson, C. (2015). Procedural Rhetoric Beyond Persuasion: First Strike and the Compulsion to Repeat. Games and Culture, 10(5), 463-480.

Moberly, K. (2013). Preemptive Strikes: Ludology, Narratology, and Deterrence in Computer Game Studies. J. Thompson ve M. A. Ouelette (Ed.), The Game Culture Reader içinde (162-174). Newcastle Upon Tyne: Cambridge Scholars Publishing.

Murray, J. H. (1997). Hamlet on the Holodeck: The future of narrative in cyberspace. Cambridge: The MIT Press.

Murray, J. H. (2005). The Last Word on Ludology v Narratology. DIGRA 2005 açılış konuşmasına önsöz. Erişim 11 Mayıs 2017, https://inventingthemedium. com/2013/06/28/the-last-word-on-ludology-v-narratology-2005/

Myers, D. (2001). Play Redux: The Form of Computer Games. Ann Arbor: University of Michigan Press.

Myers, D. (2009). The Video Game Aesthetic: Play as Form. B. Perron ve M. J. P. Wolf, (Ed.), Videogame Theory Reader 2 içinde (45-64). New York: Routledge.

Oldenburg, A. (2013). Sonic Mechanics: Audio as Gameplay. Game Studies, 13(1). Erişim 10 Nisan 2016, http://gamestudies.org/1301/articles/oldenburg_ sonic_mechanics

Raessens, J. (2006). Playful Identities, or the Ludification of Culture. Games and Culture, 1(1), 52-7.

Russel, S. (1962). Spacewar! [Oyun].

Saussure, F. (1974). Course in General Linguistics. New York, Toronto, London: McGraw-Hill Book Company.

Sayılgan, Ö. (2014). Etkileşimli Drama Olarak Dijital Oyunlar Ve 'Etkileşimliliğin ideolojisi' Bağlamında Oyuncu Alımlama Pratikleri. Yayınlanmamış doktora tezi, İstanbul Üniversitesi.

Scott, R. (1982). Blade Runner [Film].

Sicart, M. (2011). Against Procedurality. Game Studies - The International Journal Of Computer Game Research. 11(3). Erişim 11 Mayıs 2017, http://gamestudies. org/1103/articles/sicart_ap

Suzuki, Y. (1999). Shenmue. SEGA [Oyun]. 
Švelch, J. (2016). Platform Studies, Computational Essentialism, and Magic: The Gathering. Erişim 15 Ekim 2017, http://analoggamestudies.org/byline/jan-svelch/ Teli M., Paoli, S. ve Maiolini, C. (2012). Digital Games And The Communication Of Health Problems. A Review Of Games Against The Concept Of Procedural Rhetoric. GAME - The Italian Journal of Game Studies. 1/2012. Erişim 12 Mayıs 2017, http://www.gamejournal.it/digital-games-and-the-communication-ofhealth-problems-a-review-of-games-against-the-concept-of-procedural-rhetoric/

Vella, D. (2015). No Mastery Without Mystery: Dark Souls and the Ludic Sublime. Game Studies, 15(1). Erişim 10 Nisan 2016, http://gamestudies.org/1501/articles/ vella 